\title{
Synthesis and characterization of bifunctional terbium complex-based nanoparticles
}

\author{
LU RuiHua, HE Jiang*, HUANG LiZhen, GE Xia, DU XiaoYan \& ZHU Jie \\ State Key Laboratory of Applied Organic Chemistry, Lanzhou University, Lanzhou 730000, China
}

Received February 24, 2011; accepted May 6, 2011

Novel bifunctional terbium complex-based nanoparticles were developed using a modified Stöber method and a layer-by-layer assembly process. A magnetic core of $\mathrm{Fe}_{3} \mathrm{O}_{4}$ nanoparticles was coated with a silica shell to form the first layer. Then a ternary $\mathrm{Tb}^{3+}$ complex (TESPPA-Tb), which acted as a luminescent marker, was covalently bound to the silica surface by stable $\mathrm{Si}-\mathrm{O}-\mathrm{Si}$ bonds. The TESPPA monomer was synthesized by binding pyridine 2,6-dicarboxylic acid to 3-aminopropyltriethoxysilane, which was used as a ligand for coordination with the $\mathrm{Tb}^{3+}$ ions. An outer shell of silica was applied to the nanoparticles to allow for versatility with surface functionalization. The nanoparticles were characterized by X-ray powder diffraction, transmission electron microscopy, Fourier transform infrared spectroscopy, ultraviolet-visible spectroscopy, vibration sample magnetometer, and photoluminescence spectroscopy. The bifunctional nanoparticles exhibited favorable superparamagnetic behavior and photoluminescence properties of $\mathrm{Tb}^{3+}$. These nanoparticles have potential applications in biolabeling, bioseparation, immunoassays, and pathogenic diagnosis.

composite material, magnetic property, luminescence, lanthanide complex

Citation: $\quad$ Lu R H, He J, Huang L Z, et al. Synthesis and characterization of bifunctional terbium complex-based nanoparticles. Chin Sci Bull, 2012, 57: 750-755, doi: 10.1007/s11434-011-4661-2

Multifunctional nanocomposites with magnetic cores and luminescent shells have received much attention in recent years because of their potential biomedical and biological applications in the magnetic separation and detection of cancer cells, bacteria and viruses [1]. Magnetic nanoparticles (NPs) have been employed in many advanced technologies, such as targeted drug delivery [2], cell labeling [3], cell separation [4], immunoassays [5], magnetic resonance imaging [6-8], and magnetic hyperthermia [9]. Superparamagnetic NPs can be attracted by a magnetic field, but retain no residual magnetism after the field is removed, which means they can be easily separated from a matrix without agglomeration after removal of the magnetic field. Microor nanocomposites that combine superparamagnetic and optical properties into a single system have potential applications in the biomedical and biopharmaceutical fields and have attracted much attention [10]. Luminescent NPs such

*Corresponding author (email: hejiang@1zu.edu.cn) as quantum dots and dye-doped NPs have been used as biolabels in bioassays, and these have advantages over traditional fluorophores [11-13]. However, quantum dots have poor water-solubility, difficult surface conjugation chemistry, and possible toxicity in vivo, and are still under investigation [14,15]. Organic dye-doped NPs have broad emission and small Stokes shift, which results in interference between the excitation and emission signals. These limitations hinder the application of quantum dots and dye-doped NPs.

Compared with these fluorophores, luminescent lanthanide complexes, especially those of $\mathrm{Tb}^{3+}$ and $\mathrm{Eu}^{3+}$, have large Stokes shifts and strong narrow emission bands in the visible region, which are crucial for low detection limits and high sensitivity in fluorescence detection. They also have long fluorescence lifetimes (micro- to milliseconds range), which allow the removal of background fluorescence and increased assay sensitivity in time-resolved measurements, and can provide accurate and highly sensitive quantification 
of specific targets [16,17]. The lanthanide complexes are also more photostable and less prone to photobleaching than organic fluorophores [18]. These unique properties make them ideal as specific reporters in fluorescence detection of biomolecules and high throughout assays [19-21]. Combination of magnetic NPs $\left(\mathrm{Fe}_{3} \mathrm{O}_{4}\right)$ with lanthanide complexes would produce a new type of bifunctional magnetic-optical NP that have the advantages of both magnetic NPs and lanthanide ions, and these NPs could have increased potential in biology and biomedicine [22].

Lanthanide complexes of pyridine-2,6-dicarboxylic acid (PDA) and their substituted derivatives have interesting photophysical properties [23-25]. PDA has two carboxylic functional groups and a nitrogen atom with nonbonding electrons to form stable complexes with metal ions. It has been used as a model compound of natural organic matter to form stable complexes [26]. The lanthanide complexes of PDA have been used widely in analysis [27].

In the present study, a monomer (TESPPA) was made from PDA bound to 3-aminopropyltriethoxysilane (APTES), which was used as a ligand to coordinate the monomer with $\mathrm{Tb}^{3+}$. Novel bifunctional NPs were prepared by binding the TESPPA-Tb complex to silica coated $\mathrm{Fe}_{3} \mathrm{O}_{4}$ magnetic NPs $\left(\mathrm{Fe}_{3} \mathrm{O}_{4} @ \mathrm{SiO}_{2}\right)$, which were prepared through a modified Stöber method (Scheme 1). The NPs were coated with an outer shell of silica, and their magnetic and luminescent behaviors were studied. These NPs have promising applications in simultaneous biolabeling, imaging, cell sorting, and separation.

\section{Experimental}

\subsection{Materials and measurement}

Ferric chloride hexahydrate $\left(\mathrm{FeCl}_{3} \cdot 6 \mathrm{H}_{2} \mathrm{O}\right)$, ferrous sulfate

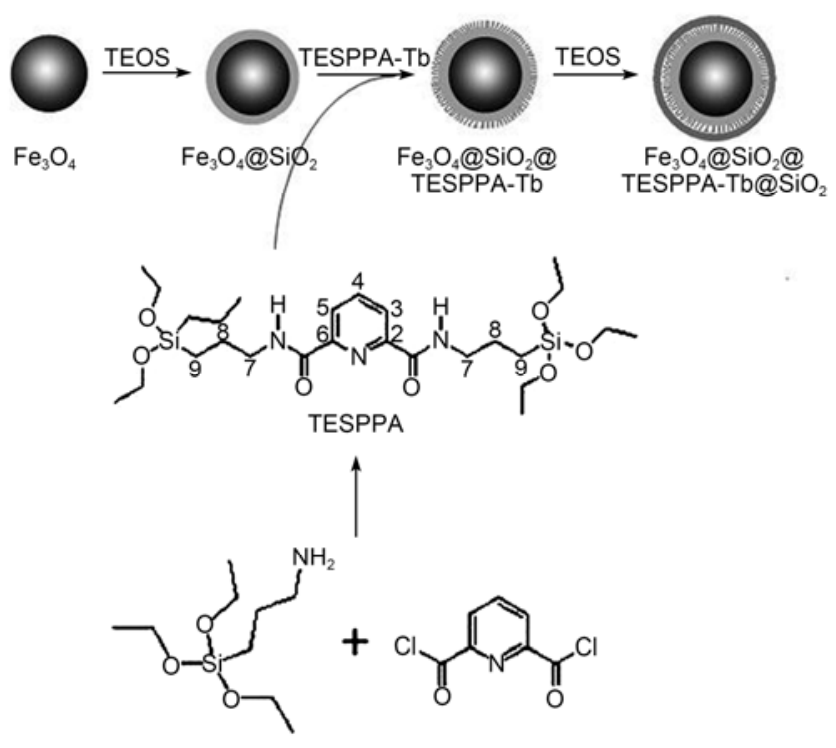

Scheme 1 Preparation of the bifunctional NPs. heptahydrate $\left(\mathrm{FeSO}_{4} \cdot 7 \mathrm{H}_{2} \mathrm{O}\right)$ and ammonium hydroxide (25\%-28\%) were purchased from Beijing Chemical Reagent Co., Ltd (Beijing, China). Tetraethoxysilane (TEOS) was obtained from Tianjin Chemical Reagent Factory (Tianjin, China). PDA (AR grade) and APTES (Gaizhou Chemical Industrial Co., Liaoning, China) were used as received. $\mathrm{TbCl}_{3}$ ethanol solution was obtained by reaction of $\mathrm{Tb}_{4} \mathrm{O}_{7}$ (99.999\% purity, Lianyungang Ligang Rare Earth Manufacturing Co., Ltd, Jiangsu, China) with $\mathrm{HCl}$ solution (6.0 mol/L). Deionized water was used throughout the experiments. All other materials were of analytical grade and used as received.

\subsection{Synthesis of $\mathrm{Fe}_{3} \mathrm{O}_{4}$ magnetic NPs}

An iron oxide dispersion was prepared using an established method [28]. Briefly, $\mathrm{FeCl}_{3} \cdot 6 \mathrm{H}_{2} \mathrm{O}(5.838 \mathrm{~g}, 0.0216 \mathrm{~mol}$ ) and $\mathrm{FeSO}_{4} \cdot 7 \mathrm{H}_{2} \mathrm{O}(3.003 \mathrm{~g}, 0.0108 \mathrm{~mol})$ were dissolved in $100 \mathrm{~mL}$ of deoxygenated water at $85^{\circ} \mathrm{C}$ under vigorous mechanical stirring in a nitrogen atmosphere. Then, $7.5 \mathrm{~mL}$ of ammonium hydroxide was quickly injected into the reaction mixture. This resulted in immediate formation of a black precipitate of magnetic NPs. The magnetite dispersion was stirred for $30 \mathrm{~min}$ and then cooled to room temperature. The black precipitate was washed several times with deionized water and twice with $0.02 \mathrm{~mol} / \mathrm{L}$ sodium chloride by magnetic decantation.

\subsection{Synthesis of silica-coated magnetic NPs $\left(\mathrm{Fe}_{3} \mathrm{O}_{4} @ \mathrm{SiO}_{2}\right)$}

The silica-coated magnetic NPs were prepared via a modified Stöber sol-gel process [29]. A suspension of the synthesized magnetic NPs $(0.1 \mathrm{~g})$ was diluted in a mixture of ethanol $(40 \mathrm{~mL})$ and water $(8 \mathrm{~mL})$. After addition of ammonia solution $(1 \mathrm{~mL})$, TEOS $(0.5 \mathrm{~mL})$ was added to the reaction solution with mechanical stirring at $25^{\circ} \mathrm{C}$ for $4 \mathrm{~h}$. The products were obtained by magnetic separation and washed four times with water and then ethanol.

\subsection{Synthesis of $\mathrm{Fe}_{3} \mathrm{O}_{4} @ \mathrm{SiO}_{2} @ \mathrm{TESPPA}-\mathrm{Tb} @ \mathrm{SiO}_{2} \mathrm{NPs}$}

(i) Synthesis of pyridine 2,6-dicarbonyl dichloride. Pyridine 2,6-dicarbonyl dichloride was synthesized by dissolving pyridine 2,6-dicarboxylic acid in the fresh $\mathrm{SOCl}_{2}$ [30]. The reaction mixture was stirred and refluxed for $6 \mathrm{~h}$ under a nitrogen atmosphere. Then the surplus $\mathrm{SOCl}_{2}$ was evaporated under reduced pressure. A white solid (yield 99.5\%) was obtained after drying the residue under vacuum. The crude product was used in next reaction directly without purification.

(ii) Synthesis of the modified precursor TESPPA. The silica precursor TESPPA was prepared by dissolving $0.4000 \mathrm{~g}$ $(1.96 \mathrm{mmol})$ of 2,6-pyridinedicarboxylic acid chloride in $40 \mathrm{~mL}$ of dry diethyl ether and degassing under argon [31]. 
A solution of APTES $(0.8680 \mathrm{~g}, 3.92 \mathrm{mmol})$ and pyridine $(0.3408 \mathrm{~g}, 4.31 \mathrm{mmol})$ in $20 \mathrm{~mL}$ of diethyl ether was then added dropwise to the mixture. The resultant solution was stirred under argon for $5 \mathrm{~h}$ at room temperature. After removing the precipitated pyridinium chloride and the solvent, the residue was isolated and further dried under vacuum, which gave the ligand TESPPA as a clear yellow oil. ${ }^{1} \mathrm{HNMR}\left(\mathrm{CDCl}_{3}, 400 \mathrm{MHz}\right) \delta: 8.61\left(2 \mathrm{H}, \mathrm{H}_{3}-\mathrm{H}_{5}\right), 8.24(2 \mathrm{H}$, $\mathrm{NH}), 8.05\left(1 \mathrm{H}, \mathrm{H}_{4}\right), 4.04\left(12 \mathrm{H}, \mathrm{CH}_{2}(\mathrm{OEt})\right), 3.46\left(4 \mathrm{H}, \mathrm{H}_{7}\right)$, $1.74\left(4 \mathrm{H}, \mathrm{H}_{8}\right), 1.26\left(1 \mathrm{H}, \mathrm{CH}_{3}(\mathrm{OEt})\right), 0.85\left(4 \mathrm{H}, \mathrm{H}_{9}\right)$. The data were consistent with a previous report [31].

(iii) Covalent coupling of TESPPA to the silica-coated magnetic NP surface $\left(\mathrm{Fe}_{3} \mathrm{O}_{4} @ \mathrm{SiO}_{2} @\right.$ TESPPA). TESPPA $(50 \mathrm{mg})$ was dissolved in $10 \mathrm{~mL}$ of ethanol by ultrasonication. Then the TESPPA solution was added to $100 \mathrm{~mL}$ of an ethanol solution of $\mathrm{Fe}_{3} \mathrm{O}_{4} @ \mathrm{SiO}_{2} \mathrm{NPs}$ mixed with $1 \mathrm{~mL}$ of $\mathrm{H}_{2} \mathrm{O}$. After reaction at $80^{\circ} \mathrm{C}$ for $4 \mathrm{~h}$, the TESPPA modified $\mathrm{Fe}_{3} \mathrm{O}_{4} @ \mathrm{SiO}_{2} \mathrm{NPs}\left(\mathrm{Fe}_{3} \mathrm{O}_{4} @ \mathrm{SiO}_{2} @ \mathrm{TESPPA}\right)$ were obtained and washed with ethanol and $\mathrm{H}_{2} \mathrm{O}$.

(iv) Chelation of the $\mathrm{Tb}^{3+}$ ions with the $\mathrm{Fe}_{3} \mathrm{O}_{4} @ \mathrm{SiO}_{2} @$ TESPPA NPs. The $\mathrm{Fe}_{3} \mathrm{O}_{4} @ \mathrm{SiO}_{2} @$ TESPPA product was dispersed in $100 \mathrm{~mL}$ of ethanol by ultrasonication. An excess of $\mathrm{TbCl}_{3}(0.01 \mathrm{~mol} / \mathrm{L}$ in ethanol $)$ was added with vigorous stirring, and the mixture was allowed to react at $80^{\circ} \mathrm{C}$ for $6 \mathrm{~h}$. The resultant $\mathrm{Fe}_{3} \mathrm{O}_{4} @ \mathrm{SiO}_{2} @$ TESPPA-Tb NPs were purified using a magnet and washed with ethanol three times.

(v) Silica coating of the $\mathrm{Fe}_{3} \mathrm{O}_{4} @ \mathrm{SiO}_{2} @$ TESPPA-Tb NPs. The $\mathrm{Fe}_{3} \mathrm{O}_{4} @ \mathrm{SiO}_{2} @$ TESPPA-Tb NPs were dispersed by ultrasonication in a solution containing $\mathrm{NH}_{3} \cdot \mathrm{H}_{2} \mathrm{O}(0.5 \mathrm{~mL})$, ethanol $(40 \mathrm{~mL})$, and deionized water $(10 \mathrm{~mL})$. Then TEOS $(0.2 \mathrm{~mL})$ was injected into the solution slowly, and the mixture was allowed to react at room temperature for $5 \mathrm{~h}$. Hydrolysis and condensation of TEOS encapsulated the NPs in a silica outer shell. The suspension was separated magnetically, and the NPs were washed with water and ethanol three times and then dried at $50^{\circ} \mathrm{C}$ for $8 \mathrm{~h}$.

\subsection{Characterization}

Powder X-ray diffraction (XRD) patterns were recorded using a X'Pertpro X-ray diffractometer (PANalytical) using $\mathrm{Cu} \mathrm{K} \alpha$ radiation $(\lambda=1.514056 \AA)$ at $2 \theta=20^{\circ}-80^{\circ}$. A Nicolet AVATAR 360 Fourier transform infrared (FT-IR) spectrometer was used to study the synthesized composites at $4000-400 \mathrm{~cm}^{-1}$. ${ }^{1} \mathrm{H}$ NMR spectra were recorded on a Varian Mercury Plus-400 spectrometer. The morphologies and sizes of the samples were characterized using a Hitachi-600 transmission electron microscope (TEM), and their magnetic properties were investigated using a vibrating sample magnetometer (VSM-5, Toei Kogyo Co., Ltd.). Ultraviolet-visible (UV-Vis) absorption spectra were recorded with a TU-1810 (Pgeneral) spectrophotometer. Photoluminescence (PL) spectra were measured at room temperature by a RF-5301 spectrofluorometer (Shimadzu, Japan) equipped with a xenon lamp as the excitation light source.

\section{Results and discussion}

\subsection{Structure of the $\mathrm{Fe}_{3} \mathrm{O}_{4} \mathrm{NPs}$}

The crystal structures of the NPs were obtained by XRD. The data for the $\mathrm{Fe}_{3} \mathrm{O}_{4}$ particles (Figure 1(a)) corresponded to the standard $\mathrm{Fe}_{3} \mathrm{O}_{4}$ powder diffraction data (JCPDS card: 89-691), which indicates that they are pure and belong to the cubic crystal system. The XRD pattern of the $\mathrm{Fe}_{3} \mathrm{O}_{4} @ \mathrm{SiO}_{2}$ NPs (Figure 1(b)) was in good agreement with that of $\mathrm{Fe}_{3} \mathrm{O}_{4}$ phase, except for a strong broad peak around $2 \theta=22^{\circ}$ corresponding to amorphous phase of silica. This indicates that the NPs obtained after the coating process are composed of $\mathrm{Fe}_{3} \mathrm{O}_{4}$ and amorphous $\mathrm{SiO}_{2}$. The application of Scherrer's formula to the (311) reflection peak at $2 \theta=36^{\circ}$ indicated the $\mathrm{Fe}_{3} \mathrm{O}_{4} \mathrm{NPs}$ had a mean diameter of approximately $12.5 \mathrm{~nm}$.

\subsection{Morphology of the $\mathrm{Fe}_{3} \mathrm{O}_{4} @ \mathrm{SiO}_{2} @ \mathrm{TESPPA}-\mathrm{Tb} @$ $\mathrm{SiO}_{2} \mathrm{NPs}$}

TEM images were obtained of the $\mathrm{Fe}_{3} \mathrm{O}_{4}$ NPs (Figure 2(a)) and the $\mathrm{Fe}_{3} \mathrm{O}_{4} @ \mathrm{SiO}_{2} @$ TESPPA-Tb@SiO $\mathrm{Si}_{2}$ NPs (Figure 2(b)). The $\mathrm{Fe}_{3} \mathrm{O}_{4}$ NPs were spherical with an average effective diameter of about $13 \mathrm{~nm}$, which is similar to the XRD results. The bifunctional NPs had a mean diameter of $70 \mathrm{~nm}$, and most were a regular spherical shape. The bifunctional NPs were obviously larger than the bare $\mathrm{Fe}_{3} \mathrm{O}_{4} \mathrm{NPs}$, and the increase in size can be attributed to the silica layers and the TESPPA-Tb complex. The monolayer of the TESPPA-Tb complex was too thin to be observed by TEM, which made it was difficult to differentiate the inner silica layer from the outer silica layer in the TEM image.

The covalent $\mathrm{Si}-\mathrm{O}-\mathrm{Si}$ bonds between TESPPA and the $\mathrm{Fe}_{3} \mathrm{O}_{4} @ \mathrm{SiO}_{2} \mathrm{NPs}$ are probably formed by replacement of the alkoxide groups $-\mathrm{OC}_{2} \mathrm{H}_{5}$ of TESPPA with hydroxyl

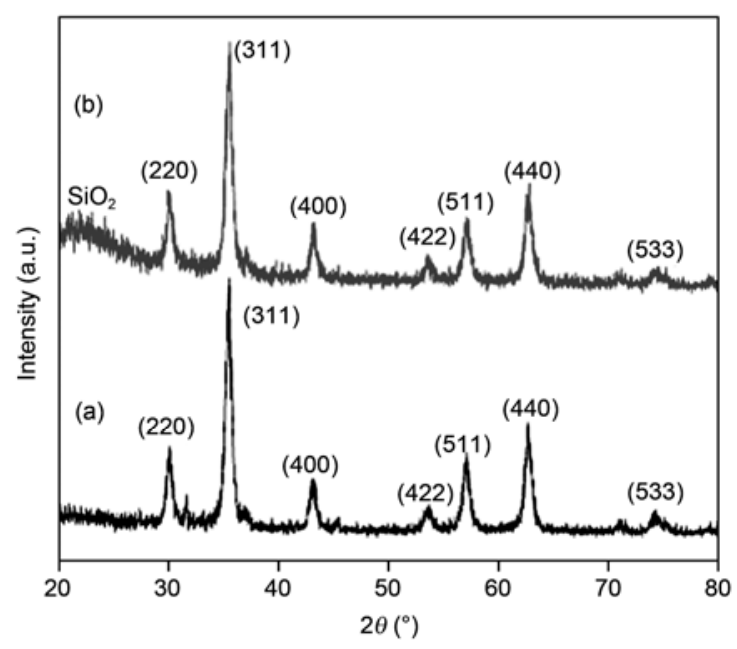

Figure 1 XRD patterns of $\mathrm{Fe}_{3} \mathrm{O}_{4}(\mathrm{a})$ and $\mathrm{Fe}_{3} \mathrm{O}_{4} @ \mathrm{SiO}_{2}$ (b). 


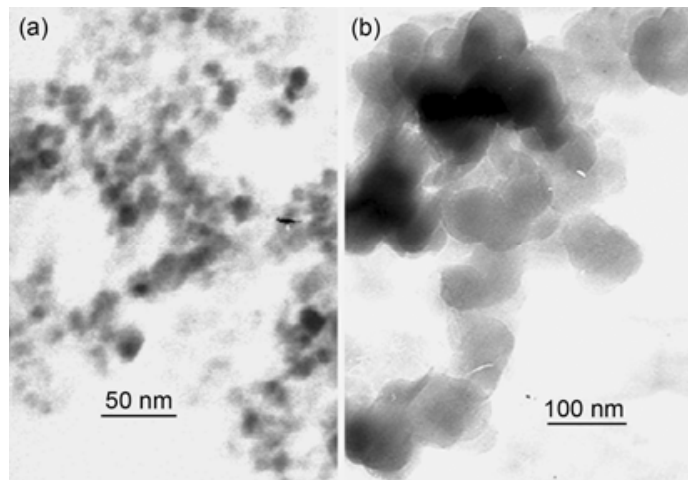

Figure 2 TEM images of the $\mathrm{Fe}_{3} \mathrm{O}_{4}$ nanoparticles (a) and the bifunctional NPs (b).

groups $(\mathrm{OH})$ by hydrolysis to form reactive silanol groups, which then condense with free $\mathrm{OH}$ groups of the magnetic silica surface. This covalent linking of the complex TESPPA$\mathrm{Tb}$ would effectively eliminate fluorescence leaking.

Successful covalent linking of TESPPA on the surface of $\mathrm{Fe}_{3} \mathrm{O}_{4} @ \mathrm{SiO}_{2}$ was proved by FT-IR. The FT-IR spectra for $\mathrm{Fe}_{3} \mathrm{O}_{4} @ \mathrm{SiO}_{2}(\mathrm{a})$, TESPPA (b) and $\mathrm{Fe}_{3} \mathrm{O}_{4} @ \mathrm{SiO}_{2} @ \mathrm{TESPPA}-$ $\mathrm{Tb} @ \mathrm{SiO}_{2}(\mathrm{c})$ are shown in Figure 3. Iron oxide was identified by an absorption peak at $568 \mathrm{~cm}^{-1}$ (Figure 3(a)) for the stretching vibration of the $\mathrm{Fe}-\mathrm{O}$ functional group. The bands at 1097 and $467 \mathrm{~cm}^{-1}$ correspond to $\mathrm{Si}-\mathrm{O}-\mathrm{Si}$ and $\mathrm{Si}-\mathrm{O}-\mathrm{Fe}$ stretching vibrations of the silica shell. The absorption bands at 957 and $797 \mathrm{~cm}^{-1}$ are from the stretching of $\mathrm{Si}-\mathrm{O}-\mathrm{H}$ and vibrations of $\mathrm{OH}$ on the surface of the magnetite. The linking of the TESPPA-Tb complex supported by the band at $1656 \mathrm{~cm}^{-1}$, which originates from the absorption of amide groups (-CONH-) (Figure 3(b)). The presence of the bending vibration $\left(\delta_{\mathrm{NH}}, 1547 \mathrm{~cm}^{-1}\right)$ is further evidence for the formation of amide groups. In addition, two sharp peaks at 2926 and $2856 \mathrm{~cm}^{-1}$ arose from methylene vibrations $-\left(\mathrm{CH}_{2}\right)_{3}-$ in APTES, which showed that

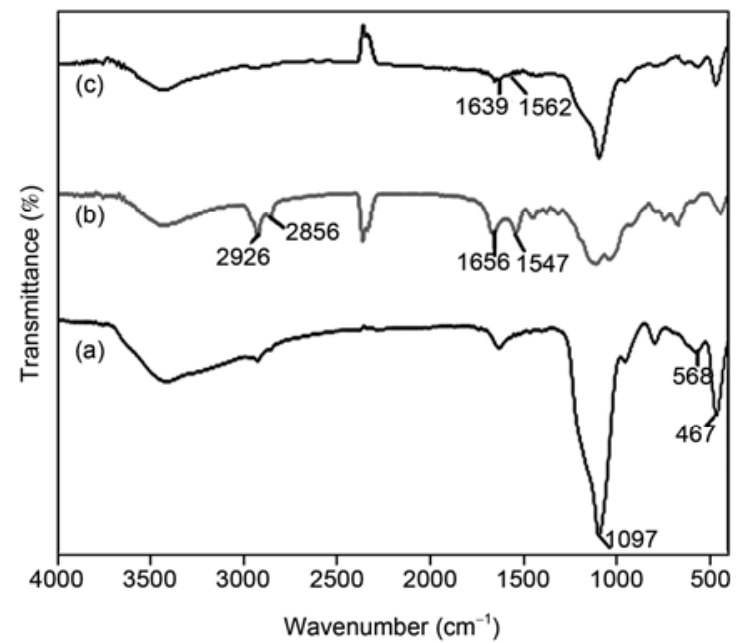

Figure 3 IR spectra of the $\mathrm{Fe}_{3} \mathrm{O}_{4} @ \mathrm{SiO}_{2} \mathrm{NPs}$ (a), TESPPA (b) and $\mathrm{Fe}_{3} \mathrm{O}_{4} @ \mathrm{SiO}_{2} @ \mathrm{TESPPA}-\mathrm{Tb} @ \mathrm{SiO}_{2} \mathrm{NPs}(\mathrm{c})$.
APTES was successfully bound to PDA. No absorption bands characteristic of carboxylic acid chloride or carboxylic acid functions were detected in the range $1760-1720 \mathrm{~cm}^{-1}$, which is further proof of the completion of reaction. In the FT-IR spectrum of the $\mathrm{Fe}_{3} \mathrm{O}_{4} @ \mathrm{SiO}_{2} @ \mathrm{TESPPA}-\mathrm{Tb} @ \mathrm{SiO}_{2}$ NPs (Figure 3(c)), the $\mathrm{C}=\mathrm{O}$ vibration shifted to a lower frequency (from 1656 to $1639 \mathrm{~cm}^{-1}$ ) and the $\mathrm{NH}$ band shifted to a higher frequency (from 1547 to $1562 \mathrm{~cm}^{-1}$ ). These shifts are proofs of the coordination of the carboxylic group to the metal ion with the oxygen atoms [31]. These two bonds are obviously weakened in the NPs compared with those in the ligand. This can be attributed to the rigid structure of the coordinated complex, which restricts stretching or bending of the $\mathrm{C}=\mathrm{O}$ and $\mathrm{N}-\mathrm{H}$ groups [32].

\subsection{Dispersity and magnetic response of the $\mathrm{Fe}_{3} \mathrm{O}_{4} @$ $\mathrm{SiO}_{2} @ \mathrm{TESPPA}-\mathrm{Tb} @ \mathrm{SiO}_{2} \mathrm{NPs}$ in an aqueous solution under UV irradiation}

Figure 4 illustrates the dispersion and magnetic response of the NPs under UV irradiation. The magnetic NPs were easily and stably dispersed in water, and remained in suspension in the absence of an external magnetic field. Upon UV light irradiation, the suspension emitted bright-green light (Figure 4(a)) that could be attributed to the characteristic emission of $\mathrm{Tb}^{3+}$. When a magnet was placed beside the cuvette, the NPs accumulated near it within several minutes, and the bulk solution became clear and transparent. The aggregates also emitted green light (Figure 4(b)), which is direct evidence the lanthanide complex TESPPA-Tb is connected to the $\mathrm{Fe}_{3} \mathrm{O}_{4} @ \mathrm{SiO}_{2} \mathrm{NPs}$.

UV-Vis absorption spectra were obtained of the suspension of the $\mathrm{Fe}_{3} \mathrm{O}_{4} @ \mathrm{SiO}_{2} @ \mathrm{TESPPA}-\mathrm{Tb} @ \mathrm{SiO}_{2} \mathrm{NPs}$. The maximum absorption was located at around $\lambda=278 \mathrm{~nm}$ (Figure 5(a)), and could be attributed to the absorption of TESPPA-Tb. When an external magnetic field applied to the NPs, the supernatant solution showed no absorption

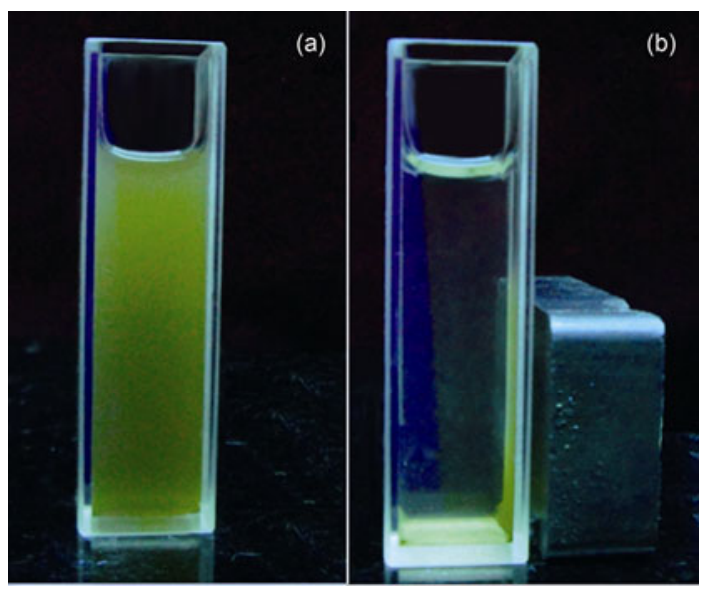

Figure 4 Photographic images of the magnetic luminescent nanoparticles under UV irradiation without (a) and with (b) an external magnetic field. 


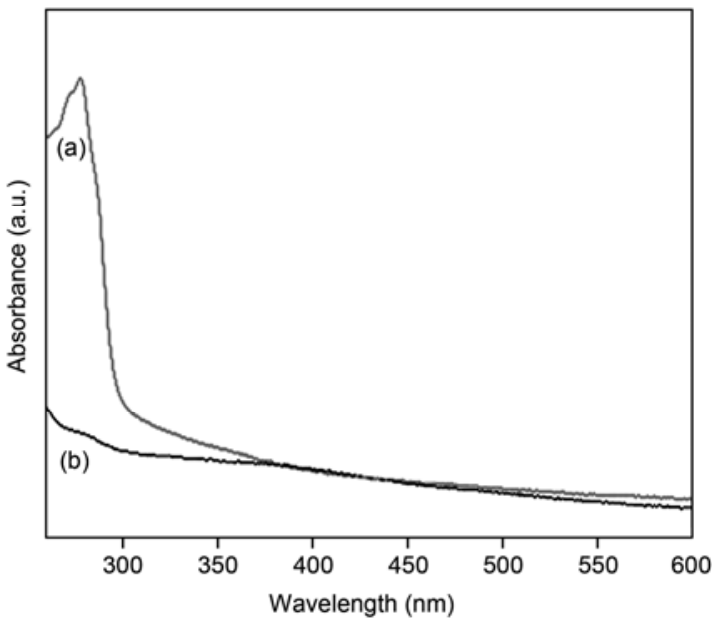

Figure 5 UV-Vis absorption spectra for a suspension of the $\mathrm{Fe}_{3} \mathrm{O}_{4} @$ $\mathrm{SiO}_{2} @ \mathrm{TESPPA}-\mathrm{Tb} @ \mathrm{SiO}_{2} \mathrm{NPs}$ without (a) and with (b) an external magnetic field.

peak (Figure 5(b)). This demonstrates formation of the bifunctional NPs, and their good magnetic separation.

\subsection{Magnetic properties of the $\mathrm{Fe}_{3} \mathrm{O}_{4} @ \mathrm{SiO}_{2} @$ TESPPA- $\mathbf{T b} @ \mathrm{SiO}_{2} \mathbf{N P s}$}

Magnetic hysteresis loops of the bare $\mathrm{Fe}_{3} \mathrm{O}_{4}$ (a), $\mathrm{Fe}_{3} \mathrm{O}_{4} @$ $\mathrm{SiO}_{2}$ (b), and $\mathrm{Fe}_{3} \mathrm{O}_{4} @ \mathrm{SiO}_{2} @ \mathrm{TESPPA}-\mathrm{Tb} @ \mathrm{SiO}_{2}$ (c) were recorded by VSM measurement at room temperature. All samples exhibited negligible coercivity and remanence (Figure 6), which demonstrates that the superparamagnetic properties of the composite NPs are retained. The saturation magnetization of the $\mathrm{Fe}_{3} \mathrm{O}_{4} @ \mathrm{SiO}_{2} \mathrm{NPs}$ was about $33.5 \mathrm{emu} / \mathrm{g}$, and this reduced to $4.3 \mathrm{emu} / \mathrm{g}$ after coating the NPs with an outer shell of silica. Both of these values were much lower than the initial saturation magnetization of $\mathrm{Fe}_{3} \mathrm{O}_{4}(67.4 \mathrm{emu} / \mathrm{g})$, which could be interpreted as the contribution of the middle

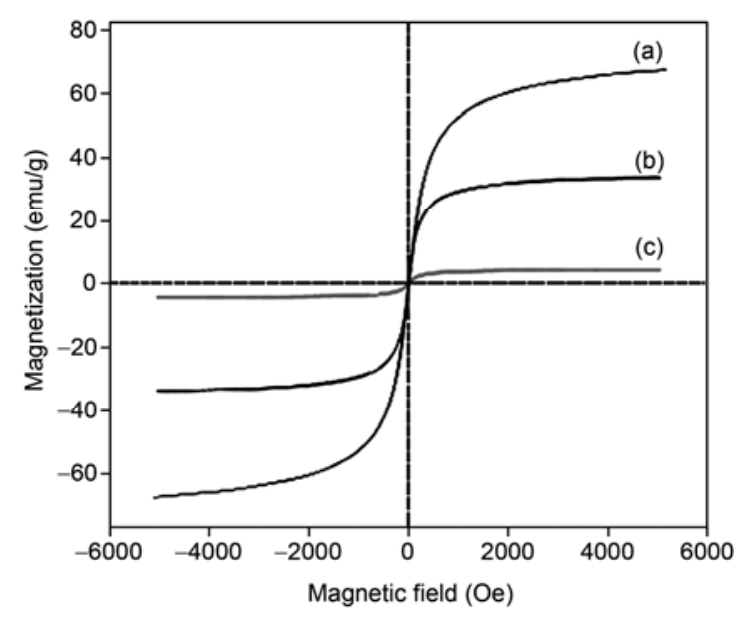

Figure 6 Magnetic hysteresis loops of $\mathrm{Fe}_{3} \mathrm{O}_{4}(\mathrm{a}), \mathrm{Fe}_{3} \mathrm{O}_{4} @ \mathrm{SiO}_{2}$ (b), and $\mathrm{Fe}_{3} \mathrm{O}_{4} @ \mathrm{SiO}_{2} @ \mathrm{TESPPA}-\mathrm{Tb} @ \mathrm{SiO}_{2}(\mathrm{c})$. and outermost silica shells. The magnetization value of the $\mathrm{Fe}_{3} \mathrm{O}_{4} @ \mathrm{SiO}_{2} @ \mathrm{TESPPA}-\mathrm{Tb} @ \mathrm{SiO}_{2}$ NPs is sufficient for bioseparation.

\subsection{Photoluminescent properties of the $\mathrm{Fe}_{3} \mathrm{O}_{4} @ \mathrm{SiO}_{2} @$ TESPPA-Tb@ $\mathrm{SiO}_{2} \mathrm{NPs}$}

The excitation and emission spectra of the $\mathrm{Fe}_{3} \mathrm{O}_{4} @ \mathrm{SiO}_{2} @$ TESPPA-Tb@ $\mathrm{SiO}_{2} \mathrm{NPs}$ are shown in Figure 7. The excitation spectrum was recorded at $\lambda_{\mathrm{em}}=545 \mathrm{~nm}$ showed a broad band centered at $286 \mathrm{~nm}$ for absorption by the ligand TESPPA, but no absorption was observed for the terbium ions. The emission spectra was recorded at $\lambda_{\mathrm{ex}}=286 \mathrm{~nm}$, and showed four emission lines for the NPs. These corresponded to the ${ }^{5} D_{4} \rightarrow{ }^{7} F_{J}$ transitions for $J=6,5,4$, and 3 at around 489, 545, 583 and $622 \mathrm{~nm}$, respectively, for the $\mathrm{Tb}^{3+}$ ions. Among these emission peaks, the green luminescence $\left({ }^{5} D_{4} \rightarrow{ }^{7} F_{5}\right)$ was the strongest, which indicated that the effective energy transfer took place between the modified ligand TESPPA and the $\mathrm{Tb}^{3+}$ ions. Both strong emission intensity and a narrow emission half width $(>15 \mathrm{~nm})$ were observed, which showed that the bifunctional NPs had high fluorescence intensity and color purity. These results further confirm that the terbium complexes were successfully linked to the silica coated magnetic NPs.

\section{Conclusions}

In summary, $\mathrm{Tb}^{3+}$ complexes were covalently immobilized on $\mathrm{Fe}_{3} \mathrm{O}_{4} @ \mathrm{SiO}_{2}$ NPs through the condensation of TESPPA with the free $\mathrm{OH}$ groups of the silica surface. This produced a novel bifunctional nanomaterial that had favorable superparamagnetic and unique lanthanide fluorescent properties. Covalent coupling of the lanthanide complexes to the silica shell gave higher chemical stability and photostability than

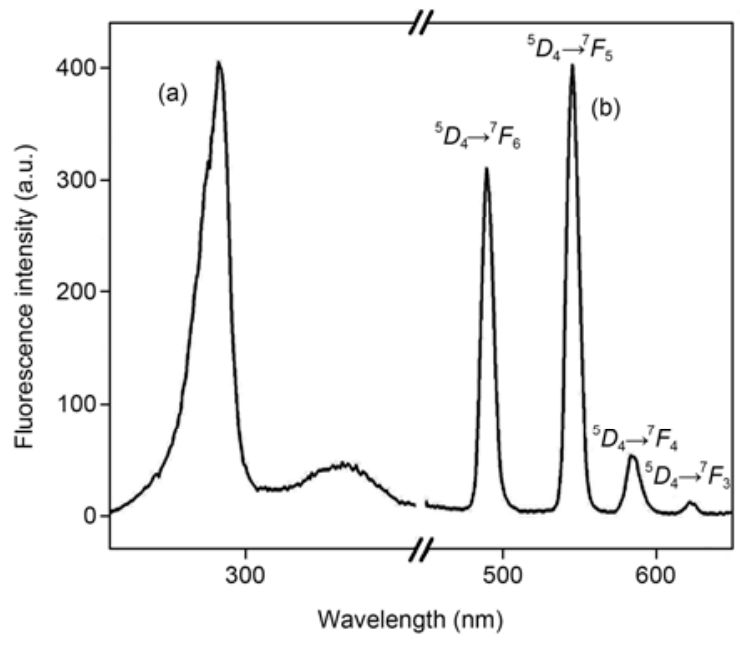

Figure 7 Excitation $\left(\lambda_{\mathrm{em}}=545 \mathrm{~nm}\right)(\mathrm{a})$ and emission $\operatorname{spectra}\left(\lambda_{\mathrm{ex}}=286 \mathrm{~nm}\right)$ (b) of the bifunctional nanoparticles. 
expected. These composite NPs could be used in biolabeling, imaging, and cell separation.

This work was supported by the National Natural Science Foundation of China (J0730425) and the Main Natural Science Foundation of Gansu Province in China (3ZSO41-A25-009).

1 Wang D S, He J B, Rosenzweig N, et al. Superparamagnetic $\mathrm{Fe}_{2} \mathrm{O}_{3}$ beads-CdSe/ZnS quantum dots core-shell nanocomposite particles for cell separation. Nano Lett, 2004, 4: 409-413

2 Yang J, Lee C H, Park J, et al. Antibody conjugated magnetic PLGA nanoparticles for diagnosis and treatment of breast cancer. J Mater Chem, 2007, 17: 2695-2699

3 Song H T, Choi J S, Huh Y M, et al. Surface modulation of magnetic nanocrystals in the development of highly efficient magnetic resonance probes for intracellular labeling. J Am Chem Soc, 2005, 127: 9992-9993

4 Schneider T, Moore L R, Jing Y, et al. Continuous flow magnetic cell fractionation based on antigen expression level. J Biochem Biophys Methods, 2006, 68: 1-21

5 Yang H H, Zhang S Q, Chen X L, et al. Magnetite-containing spherical silica nanoparticles for biocatalysis and bioseparations. Anal Chem, 2004, 76: 1316-1321

6 Jun Y W, Huh Y M, Choi J S, et al. Nanoscale size effect of magnetic nanocrystals and their utilization for cancer diagnosis via magnetic resonance imaging. J Am Chem Soc, 2005, 127: 5732-5733

7 Huh Y M, Jun Y W, Song H T, et al. In vivo magnetic resonance detection of cancer by using multifunctional magnetic nanocrystals. J Am Chem Soc, 2005, 127: 12387-12391

8 Lee J H, Huh Y M, Jun Y W, et al. Artificially engineered magnetic nanoparticles for ultra-sensitive molecular imaging. Nat Med, 2007, 13: 95-99

9 Suzuki M, Shinkai M, Honda H, et al. Anticancer effect and immune induction by hyperthermia of malignant melanoma using magnetite cationic liposomes. Melanoma Res, 2003, 13: 129-135

10 Kim H, Achermann M, Balet L P, et al. Synthesis and characterization of $\mathrm{Co} / \mathrm{CdSe}$ core/shell nanocomposites: Bifunctional magneticoptical nanocrystals. J Am Chem Soc, 2005, 127: 544-546

11 Bruchez M Jr, Moronne M, Gin P, et al. Semiconductor nanocrystals as fluorescent biological labels. Science, 1998, 281: 2013-2016

12 Chan W C W, Nie S. Quantum dot bioconjugates for ultrasensitive nonisotopic detection. Science, 1998, 281: 2016-2018

13 Tan W, Wang K, He X, et al. Bionanotechnology based on silica nanoparticles. Med Res Rev, 2004, 24: 621-638

14 Cottingham K. Quantum dots leave the light on. Anal Chem, 2005, 77: 354A-357A

15 Niemeyer C M. Nanoparticles, proteins, and nucleic acids: Biotechnology meets materials science. Angew Chem Int Ed, 2001, 40: 4128-4158

16 Petoud S, Cohen S M, Bunzli J C G, et al. Stable lanthanide lumi- nescence agents highly emissive in aqueous solution: Multidentate 2-hydroxyisophthalamide complexes of $\mathrm{Sm}^{3+}, \mathrm{Eu}^{3+}, \mathrm{Tb}^{3+}, \mathrm{Dy}^{3+}$. J Am Chem Soc, 2003, 125: 13324-13325

17 Saha A K, Kross K, Kloszewski E D, et al. Time-resolved fluorescence of a new europium-chelate complex: Demonstration of highly sensitive detection of protein and DNA samples. J Am Chem Soc, 1993, 115: 11032-11033

18 Ye Z, Tan M, Wang G, et al. Preparation, characterization, and timeresolved fluorometric application of silica-coated terbium (III) fluorescent nanoparticles. Anal Chem, 2004, 76: 513-518

19 Cha A, Snyder G E, Selvin P R, et al. Atomic scalemovement of the voltage-sensing region in a potassium channel measured via spectroscopy. Nature, 1999, 402: 809-813

20 Selvin P R. The renaissance of fluorescence resonance energy transfer. Nat Struct Biol, 2000, 7: 730-734

21 Parker D. Luminescent lanthanide sensors for $\mathrm{pH}, \mathrm{pO}_{2}$ and selected anions. Coord Chem Rev, 2000, 205: 109-130

22 Ma Z Y, Dosev D, Nichkova M, et al. Synthesis and characterization of multifunctional silica core-shell nanocomposites with magnetic and fluorescent functionalities. J Magn Magn Mater, 2009, 321: 1368-1371

23 de Sá G F, Malta O L, de Mello Donega C, et al. Spectroscopic properties and design of highly luminescent lanthanide coordination complexes. Coord Chem Rev, 2000, 196: 165-195

24 Vicentini G, Zinner L B, Zukerman-Schpector J, et al. Luminescence and structure of europium compounds. Coord Chem Rev, 2000, 196: 353-382

25 Lehn J M. Perspectives in supramolecular chemistry-From molecular recognition towards molecular information processing and self-organization. Angew Chem Int Ed, 1990, 29: 1304-1319

26 Park K K, Kwon T R, Park Y J, et al. Ternary complex formation of $\mathrm{Eu}(\mathrm{III})$ and $\mathrm{Am}(\mathrm{III})$ with pyridine-2,6-dicarboxylate in aqueous solutions. J Alloys Compd, 2007, 444-445: 677-682

27 Yin X H, Tan M Y. Studies on Iminescence poperties of Tb complexes of pyridine-2,6-dicarboxylic acid derivatives. J Chin Rare Earth Soc, 2001, 19: 555-560

28 Liu X, Ma Z, Xing J, et al. Preparation and characterization of amino-silane modified superparamagnetic silica nanospheres. J Magn Magn Mater, 2004, 270: 1-6

29 Stöber W, Fink A, Bohn E. Controlled growth of monodisperse silica spheres in the micron size range. J Colloid Interface Sci, 1968, 26: 62-69

30 An B L, Shi J X, Wong W K, et al. Synthesis and luminescence of a novel conjugated europium complex with 6-parachloroaniline carbonyl 2-pyridine carboxylic acid. J Lumin, 2002, 99: 155-160

31 Franville A C, Zambon D, Mahiou R. Luminescence behavior of solgel-derived hybrid materials resulting from covalent grafting of a chromophore unit to different organically modified alkoxysilanes. Chem Mater, 2000, 12: 428-435

32 An B L, Cheah K W, Wong W K, et al. Synthesis and luminescence of a novel conjugated europium complex with 6-paramethylaniline carbonyl 2-pyridine carboxylate. J Alloys Compd, 2003, 352: $143-147$

Open Access This article is distributed under the terms of the Creative Commons Attribution License which permits any use, distribution, and reproduction in any medium, provided the original author(s) and source are credited. 